\title{
Superparamagnetic Nanocomposite of Magnetite-Chitosan Using Oleic Acid as Anti Agglomeration and Glutaraldehyde as Crosslinkage Agent
}

\author{
Suyanta*, Sutarno, Nuryono, Bambang Rusdiarso, Eko Sri Kunarti, \\ Hesti Kusumastuti, and Lia Kurnia \\ Department of Chemistry, Faculty of Mathematics and Natural Sciences, Universitas Gadjah Mada, \\ Sekip Utara, Yogyakarta 55281, Indonesia
}

*Corresponding author:

email:suyanta_mipa@ugm.ac.id

Received: October 16, 2017

Accepted: February 8, 2018

DOI: $10.22146 /$ ijc.28989

\begin{abstract}
In this research magnetite was synthesized by coprecipitation method, in which solution of $\mathrm{NH}_{4} \mathrm{OH}$ was added into the solution containing a mixture of $\mathrm{Fe}^{2+} / \mathrm{Fe}^{3+}$ (molar ratio 1:2) until pH 11 under strong ultrasonic agitation for $30 \mathrm{~min}$. The black sediment of magnetite was filtered, washed and dried. The product was then modified by using oleic acid to prevent agglomeration. Chitosan was prepared by deacetilization of chitin, whereas chitin was extracted from shrimp shell. In the synthesis of nanocomposite, $0.5 \mathrm{~g}$ of chitosan and $1.5 \mathrm{~g}$ of oleic acid modified magnetite were introduced into $100 \mathrm{~mL}$ of $2 \%$ acetic acid solution, followed by sonication treatment for $10 \mathrm{~min}$ and magnetic stirring for $20 \mathrm{~min}$. In order to perform the cross-linkage reaction, solution of $2 \%$ glutaraldehyde was added into the mixture at temperature of $40^{\circ} \mathrm{C}$ for $3 \mathrm{~h}$. The composite was collected by magnetic separation, followed by washing with distilled water and ethanol in a row. The product was dried and characterized by XRD, FTIR, TEM and VSM methods. The result showed that the composite had good crystal structure with a cubic inverse spinel structure, monodisperse and quasi sphere in shape with diameter of 20-25 $\mathrm{nm}$. It had high saturation magnetization (43.4 emu/g) and superparamagnetic property.
\end{abstract}

Keywords: nanocomposite; magnetite; oleic acid; chitosan

\section{- INTRODUCTION}

Chitosan is a linear copolymer of linked $\beta-(1,4)$ glucosamine molecules, mainly obtained by deacetylation of chitin (poly- $\beta$ - $(1,4)$-acetylglucosamine); whereas chitin can be obtained from wastes of the seafood industry (crab and shrimp shells) involves some steps, i.e.: demineralization, deproteinization, and decolorization [1-2]. Chitosan can be used in water treatment, especially heavy metals, because the functional groups of $-\mathrm{NH}_{2}$ in the glucose ring react strongly with metal ions in a large capacity [3]. It has high porosity resulting in superior binding properties for metal ion such as cadmium, copper, lead, uranyl, mercury and chromium [4-8]. However, some weakness related to their poor chemical and mechanical stability caused it low in effectiveness and efficiency when were applied as adsorbent in the industrial scale.
One of many ideas to overcome these problem is the compositazion by using magnetite $\left(\mathrm{Fe}_{3} \mathrm{O}_{4}\right)$. This treatment leads to had better performance due to the increasing specific surface area and to the possibility to remove the used adsorbent from the contaminated waste streams by an external magnetic field in order to regenerate it for subsequent reuse [9-10].

Magnetite Nanoparticles (MNPs) has a large surface area and high affinity toward metal ions; however it tend to agglomerate lead a bulk phase which has lower in performance. Fortunately, those agglomeration can be prevented by coating with various hydrophilic compounds. Oleic acid (OA) is probably the most common small molecule which can formed the complex with magnetite [11]. OA possesses a non-polar hydrocarbon tail and a polar carboxylic acid head group. Carboxylate anions are known to coordinate with the 
surface of magnetite, presumably through a coordination of iron atoms with both the carboxylate oxygens [12].

Compositazion of chitosan with modified MNPs favor the generation of hydrogen bonding between positively partial charged hydrogen of chitosan and negatively partial charged oxygen of $\mathrm{Fe}_{3} \mathrm{O}_{4}$, thus improve their interfacial combination [13]. On the other hand cross-linking reaction can significantly alter the molecular structure of materials, therefore the properties of cross-linked materials could significantly differ from those of the original materials.

In this work, chitosan was extracted from shrimp shell, while magnetite was synthesized and modified by using oleic acid to prevent agglomeration and get the nano scale. Chitosan was then interacted with nanoparticle magnetite to obtain a nanocomposite in which chitosan has higher surface area, moreover the material can be quickly separated using external magnetic field. Finally, nanocomposite particles were cross-linkage by using glutaraldehyde to improve the stability.

\section{- EXPERIMENTAL SECTION}

\section{Materials}

Iron(III) chloride hexahydrate $\left(\mathrm{FeCl}_{3} \cdot 6 \mathrm{H}_{2} \mathrm{O}\right)$, iron(II) sulfate heptahydrate $\left(\mathrm{FeSO}_{4} \cdot 7 \mathrm{H}_{2} \mathrm{O}\right)$, aqueous ammonia (25\%), glutaraldehyde, acetic acid, and ethanol. All of materials were purchased from E. Merck, All chemicals are analytical grade without further purification. Shrimp shell was gained from a local culinary. Distilled water was used throughout the experiments.

\section{Instrumentation}

Infrared spectrophotometer Shimadzu FTIR8010PC, X-ray Diffractometer Shimadzu model XD-3H, Transmission Electron Microscope JEM-3010, Vibrating Sample Magnetometer (VSM Oxford 1.2H), Ultrasonic $28 \mathrm{H}$, and some support instruments.

\section{Procedure}

\section{Preparation of chitosan}

Preparation of chitosan from shrimp shells was performed using the method used by Kusumaningrum [14] and Kurnia [15], include: deproteination, demineralization, decolorization and deacetylation. In the deproteination step, $50 \mathrm{~g}$ of raw shrimp shells were introduced into $500 \mathrm{~mL}$ of $1 \mathrm{M} \mathrm{NaOH}$ solution accompanied by stirring at $65^{\circ} \mathrm{C}$ for $60 \mathrm{~min}$. It was then filtered, the solid phase was washed and dried. The product was demineralized by took into solution of $1 \mathrm{M}$ $\mathrm{HCl}$ (with proportion $1 \mathrm{~g}$ of solid phase in $15 \mathrm{~mL}$ of $\mathrm{HCl}$ solution) followed by stirring at $80{ }^{\circ} \mathrm{C}$ for $90 \mathrm{~min}$. Filtering of those mixture produced the solid of chitin. In order to omit the color, chitin was bleached by using solution of $4 \% \mathrm{NaOCl}$ (with proportion $1 \mathrm{~g}$ of chitin in $10 \mathrm{~mL}$ of $\mathrm{NaOCl}$ solution) at room temperature for 60 min, furthered by filtering. The solid phase was deacetylized by put into solution of $\mathrm{NaOH} 60 \% \mathrm{w} / \mathrm{w}$, followed by stirring at $90^{\circ} \mathrm{C}$ for $2 \mathrm{~h}$ formed a slurry. The slurry was then filtered, washed and dried to produce the powder of chitosan.

The samples of chitosan produced from varied w/w \% of $\mathrm{NaOH}$ were characterized using Fourier Transform Infrared (FTIR) spectrophotometer in the range of 400 to $4000 \mathrm{~cm}^{-1}$. The DDA of the sample were determined according to the method which was generally used. The A1320 was the peak area of the band about $1320 \mathrm{~cm}^{-1}$, the A1420 was the peak area of about $1420 \mathrm{~cm}^{-1}$ and $\mathrm{A}(1320)$ is peak for amide group and $\mathrm{A}(1420)$ is peak for amine group.

$\% \mathrm{DA}=\frac{(\mathrm{A} 1320 / \mathrm{A} 1420)-0.3822)}{0.03133}$

$\% \mathrm{DDA}=100-\% \mathrm{DA}$

where, $\mathrm{DDA}=$ degree of deacetylation $(\%)$ and $\mathrm{DA}=$ degree of acetylation (\%).

\section{Preparation of $\mathrm{Fe}_{3} \mathrm{O}_{4}$ nanoparticles}

$\mathrm{Fe}_{3} \mathrm{O}_{4}$ nanoparticles were prepared by coprecipitation method with a ferrous complex in presence of $\mathrm{NH}_{4} \mathrm{OH}$. First, $\mathrm{FeCl}_{2} \cdot 4 \mathrm{H}_{2} \mathrm{O}$ and $\mathrm{FeCl}_{3} \cdot 6 \mathrm{H}_{2} \mathrm{O}$ $\left[\mathrm{Fe}^{2+}: \mathrm{Fe}^{3+}=1: 2\right]$ were dissolved in $50 \mathrm{~mL}$ distilled water. The solution was stirred under strong ultrasonic agitation accompanied by heating at $80{ }^{\circ} \mathrm{C}$. Next, the solution of $3 \mathrm{M} \mathrm{NH}_{4} \mathrm{OH}$ was added drop-wise into those iron solution source until $\mathrm{pH} 11$ under strong ultrasonic agitation for $30 \mathrm{~min}$. The black deposit of $\mathrm{Fe}_{3} \mathrm{O}_{4}$ nanoparticles were separated by filtering and washed by distilled water three times. 


\section{Surface modification of magnetite nanoparticles with oleic acid}

The magnetite nanoparticles were well dispersed in $200 \mathrm{~mL}$ of methanol by ultrasonication. It was then added with $50 \mathrm{~mL}$ of oleic acid accompanied by constant stirring at $80{ }^{\circ} \mathrm{C}$. Nanoparticles of magnetite-oleic acid were filtered through Whatman filter paper no.1, followed by washing three times with distilled water. The magnetiteoleic acid nanoparticles were separated from the filter paper using acetone, followed by drying at room temperature to evaporate all the acetone. These materials were termed as $\mathrm{Fe}_{3} \mathrm{O}_{4}$-OA NPs.

\section{Preparation of magnetite-chitosan nanocomposite}

Chitosan $(0.5 \mathrm{~g})$ in $100 \mathrm{~mL}$ of $2.0 \mathrm{wt} . \%$ acetic acid solution was mixed with $1.5 \mathrm{~g}$ of $\mathrm{Fe}_{3} \mathrm{O}_{4}$-OA NPs in a threenecked flask. The mixture was treated with ultrasonic for $10 \mathrm{~min}$ and stirred for $20 \mathrm{~min}$. Then $2 \mathrm{~mL}$ of glutaraldehyde solution (25 wt.\%) was added into the mixture at $40{ }^{\circ} \mathrm{C}$ and crosslinking reaction was kept for 3 h. After the reaction the composites were collected through magnetic separation and were washed by distilled water and ethanol for three times. The products were dried at vacuum conditions.

\section{- RESULTS AND DISCUSSION}

\section{Characterization of Chitosan}

The FTIR spectra of shrimp shells powder, chitin and chitosan were presented in Fig. 1. The shrimp shells powder's spectrum (Fig. 1(a)) exhibited some bands at wave number 3449, 1651, and $1072 \mathrm{~cm}^{-1}$; the chitin spectrum (Fig. 1(b)) showed some new bands at wave number 3264, 3109, 2886, and $1072 \mathrm{~cm}^{-1}$ accompanied by little displacement of band from 1651 to $1628 \mathrm{~cm}^{-1}$; while chitosan spectrum (Fig. 1(c)) in brief displayed the new four bands at 1659, 1589, 1421, and $1072 \mathrm{~cm}^{-1}$ accompanied by the absence of band at $3264 \mathrm{~cm}^{-1}$ which was appeared on chitin spectrum. Those differences indicated that alteration of bonds in the materials have been occurred, from shrimp shells to chitin and from chitin to chitosan.

The absorption bands at $3449 \mathrm{~cm}^{-1}$ which appeared on all materials spectra is due to overlapping of the $\mathrm{OH}$ and $\mathrm{N}-\mathrm{H}$ stretching vibration of functional groups engaged

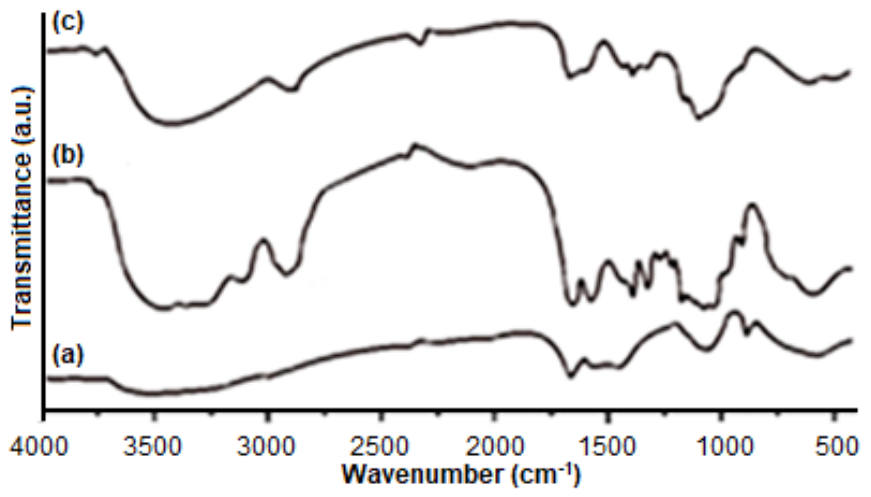

Fig 1. The FTIR spectra of shrimp shells powder (a), chitin (b) and chitosan (c) [14-15]

in hydrogen bond [16]. The bands at 3264 and $3109 \mathrm{~cm}^{-1}$ which appeared on chitin spectrum only related to vibrational modes involved in intermolecular hydrogen bonding $\mathrm{CO} \cdot \cdots \cdot \mathrm{HN}$ and the intramolecular bonds of $\mathrm{NH}$ groups, respectively [17]. The bands at $2886 \mathrm{~cm}^{-1}$ which appeared on both of chitin and chitosan spectra is due to symmetric and asymmetric $-\mathrm{CH}_{2}-$ vibration attributed to pyranose ring [18].

The two separate bands at 1659 and $1589 \mathrm{~cm}^{-1}$ on chitosan spectrum are due to $-\mathrm{C}=\mathrm{O}$ stretching (amide I) and NH stretching (amide II) [19]. In the case of both chitin and shrimp shells powder, a single peak at 1627 or $1651 \mathrm{~cm}^{-1}$ corresponds to the stretching of CO group intra-sheet chain and also showing the presence of protein [20-21]. The absorption bands from 1100 to $1020 \mathrm{~cm}^{-1}$ (included $1072 \mathrm{~cm}^{-1}$ ) which appeared on all materials spectra come from the $\mathrm{C}-\mathrm{O}-\mathrm{C}$ and $\mathrm{C}-\mathrm{O}$ stretching vibrations of the structure [22]. The other bands that are observed in the region of $1380-1460 \mathrm{~cm}^{-1}$ are attributed to the symmetric and asymmetric bending vibrations of the methyl groups [23].

The DDA in this work is large enough $(86.88 \%)$, indicating the good efficiency for this process in this established condition. Those value is also very near to that reported by some researchers. Al Sagheer et al. [15] reported that the chitosan DDA obtained from shrimp shell waste in Arabian Gulf ranged from $88-94 \%$ by using traditional method. Nouri et al. [24] also obtained DDA value ranged from $71.02-82.20 \%$ for deacetylation using traditional method while $79.01-88.60 \%$ for using microwave method. Besides, Alishahi et al. [25] also performed deacetylation by using microwave and obtained chitosan with DDA value ranged from $87.5-93 \%$. 


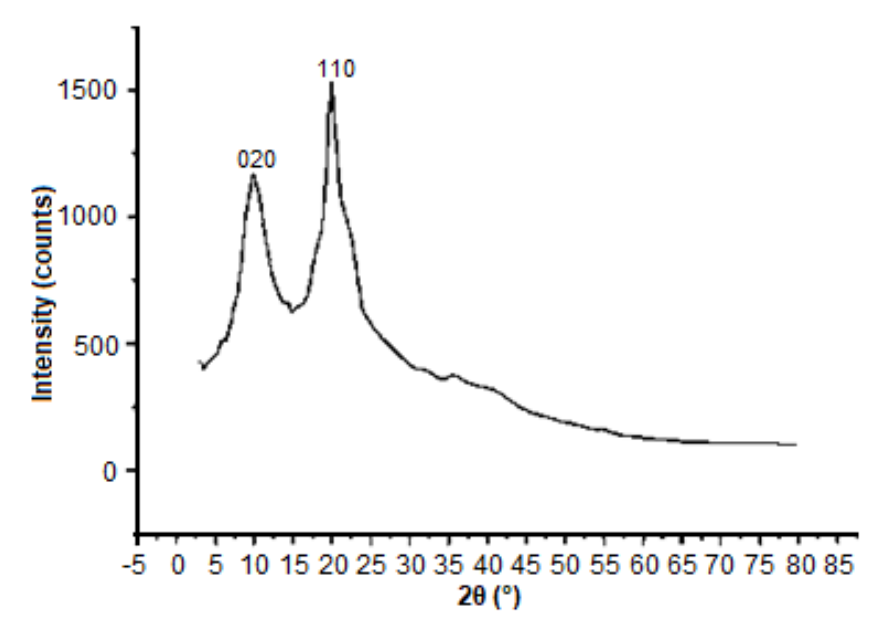

Fig 2. The XRD pattern for chitosan [14-15]

XRD analysis is based on constructive interference of monochromatic X-rays. It is a non-destructive technique widely used to investigate the interlayer changes and the crystalline properties of the synthesized material. The inter-planer distances may be calculated by the following Braggs'equation.

$\mathrm{n} \lambda=2 \mathrm{~d}_{\mathrm{hkl}} \sin \theta$

where $\lambda$ is the wavelength of the $\mathrm{X}$-ray, $\theta$ is the scattering angle, $\mathrm{n}$ is an integer representing the order of the diffraction peak, $d$ is the inter planer distance of the lattices, and (hkl) are the Miller indices [18].

The obtained XRD pattern for chitosan measured in the range of $2 \theta=10-40^{\circ}$ (Fig. 2) showed two characteristic reflections at 9.93 and $19.98^{\circ}$ that are typical fingerprints of semi crystalline chitosan indexed as (020) and (110) known as hydrated crystalline structure and an amorphous structure of chitosan [26]. Yen and Mau [27] found that fungal chitosan showed two crystalline reflections at 9.7 and $19.9^{\circ}$. This is caused by presence of plenty of $-\mathrm{OH}$ and $-\mathrm{NH}_{2}$ groups in the chitosan structure, which could form stronger inter and intramolecular hydrogen bonds and the chitosan structure has certain regularity, so that the molecules form crystalline regions easily. It is also reported that the two characteristic crystalline peaks with slightly fluctuated diffraction angles found in the wide-angle X-ray diffraction (WAXD) patterns indicated that two types of $\alpha$ - and $\gamma$-chitosan exhibited comparable degree of crystallinity and had two consistent peaks of $9-10^{\circ}$ and $19-20^{\circ}$ [28].

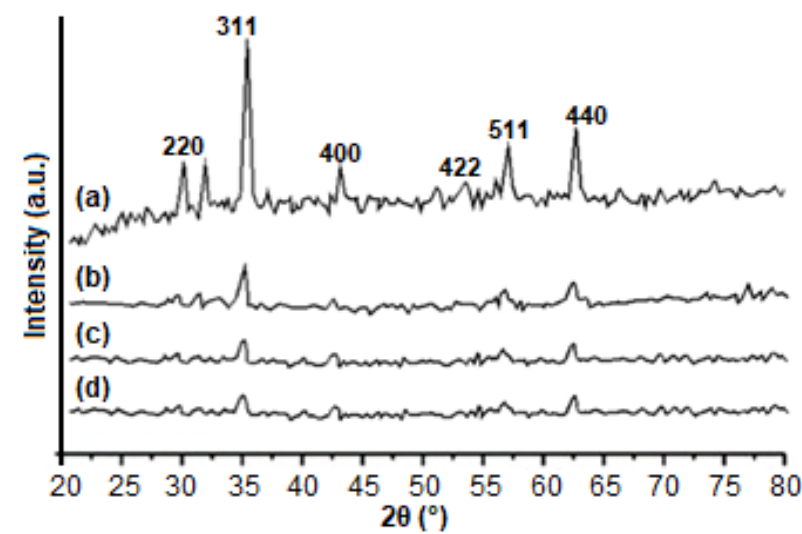

Fig 3. XRD patterns of the pristine $\mathrm{Fe}_{3} \mathrm{O}_{4}(\mathrm{a})$, and $\mathrm{Fe}_{3} \mathrm{O}_{4}$ MNPs coated with 1,2 and $3 \mathrm{~mL}$ of $\mathrm{OA}$ in modification (b, c, and d) [14-15]

\section{Characterization of Magnetite and Oleic Acid Modified Magnetite}

Fig. 3 shows the XRD patterns of the pristine $\mathrm{Fe}_{3} \mathrm{O}_{4}$ (a), and $\mathrm{Fe}_{3} \mathrm{O}_{4}$ MNPs coated with varied volume of $\mathrm{OA}$ (b-d). The peaks at $2 \theta=30.1,35.4,43.1,53.4,56.9$, and $62.5^{\circ}$, corresponding to $220,311,400,422,511$, and 440 Bragg reflection planes, which were observed in all of the samples. These peaks are consistent with the standard pattern of $\mathrm{Fe}_{3} \mathrm{O}_{4}$ (JCPDS no. 79-0418) with a cubic inverse spinel structure [29]. Therefore, it was confirmed that the crystalline structure of obtained magnetite nanoparticles, agreed with the structure of an inverse spinel type oxide. The presence of peaks in all of the samples indicated that the crystal structure of $\mathrm{Fe}_{3} \mathrm{O}_{4}$ NPs was not changed during the modification with oleic acid.

The capping of $\mathrm{Fe}_{3} \mathrm{O}_{4}$ with $\mathrm{OA}$ caused the broadening of peaks accompanied by descent of its intensity proportional to volume of $\mathrm{OA}$ added. It indicated that the particle size decreased after coating treatment. The coating of amorphous OA on crystalline $\mathrm{Fe}_{3} \mathrm{O}_{4}$ may induce microstrain which resulted in broadening of peaks also were reported by some researchers [30-31]. The crystallite size of oleic acid modified $\mathrm{Fe}_{3} \mathrm{O}_{4} \mathrm{NPs}$ smaller than the pristine one, indicated that the aim of oleic acid modification has achieved. The diffractogram of sample coated with $3 \mathrm{~mL}$ of OA (Fig. 4(d)) has smallest peaks, indicating the most complete coating; therefore the sample was choose for the next treatment. 


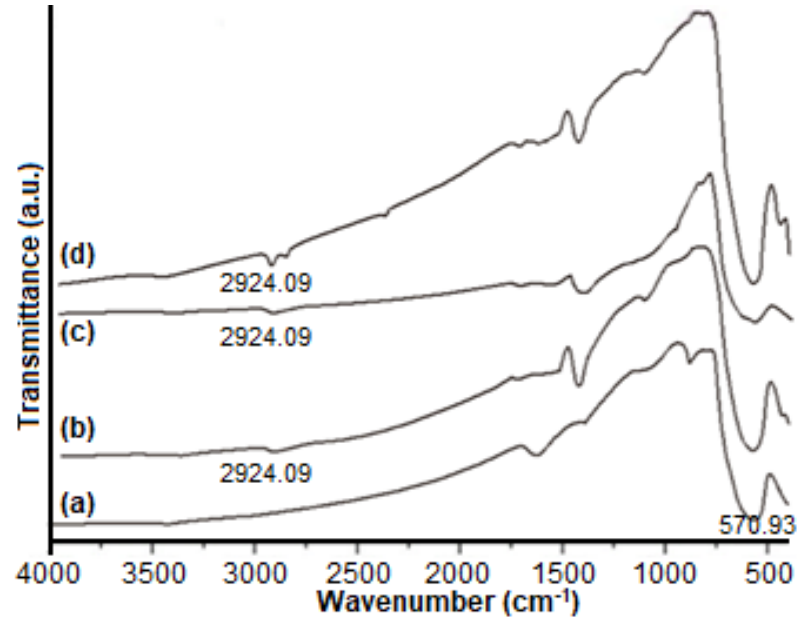

Fig 4. FTIR spectra of the pristine $\mathrm{Fe}_{3} \mathrm{O}_{4}(\mathrm{a})$, and $\mathrm{Fe}_{3} \mathrm{O}_{4}$ MNPs coated with 1,2 and $3 \mathrm{~mL}$ of $\mathrm{OA}$ in modification (b, c, and d) [14-15]

Fig. 4 shows the typical FTIR spectrum of the pristine $\mathrm{Fe}_{3} \mathrm{O}_{4}$ nanoparticles (a), and $\mathrm{Fe}_{3} \mathrm{O}_{4}$ nanoparticles coated with varied volume of oleic acid (b-d). Spectrum (a) has a sharp band only at $570 \mathrm{~cm}^{-1}$ corresponding to the $\mathrm{Fe}-\mathrm{O}$ vibration related to the magnetite phase [32], whereas the others have two extra bands at 2924 and 2854 $\mathrm{cm}^{-1}$ which attributed to the asymmetric $\mathrm{CH}_{2}$ stretch and the symmetric $\mathrm{CH}_{2}$ stretch, respectively. These extra band more and more clear when volume of $\mathrm{OA}$ added increased. In addition to the new bands at about 1500 and $1600 \mathrm{~cm}^{-1}$ which characteristic of the asymmetric and symmetric stretching of COO- group, respectively. This result proved that the bonding pattern of the carboxylic acids on the surface of $\mathrm{Fe}_{3} \mathrm{O}_{4}$ nanoparticles was a combination of molecules bonded symmetrically and molecules bonded at an angle to the surface [33].

Fig. 5 shows the FT-IR spectrum of pristine $\mathrm{Fe}_{3} \mathrm{O}_{4}$ NPs (a), oleic acid modified $\mathrm{Fe}_{3} \mathrm{O}_{4} \mathrm{NPs}(\mathrm{b})$ and $\mathrm{Fe}_{3} \mathrm{O}_{4}$-oleic acid-chitosan composite (c). The characteristic peaks of $\mathrm{Fe}_{3} \mathrm{O}_{4}$ at about $570 \mathrm{~cm}^{-1}$ could be seen in all of the three spectra which indicated the presence of $\mathrm{Fe}_{3} \mathrm{O}_{4}$. The peaks at around 3448 and $1630 \mathrm{~cm}^{-1}$ in all of them are related to the adsorbed water in the samples. The characteristic peaks of oleic acid can be observed at 2924 and $2854 \mathrm{~cm}^{-1}$ in curve (b) and (c) which related to the symmetric and asymmetric stretch of $\mathrm{CH}_{3}$ and $\mathrm{CH}_{2}$. The peaks at around 1600 and $1400 \mathrm{~cm}^{-1}$ in curve (b) and (c) due to the

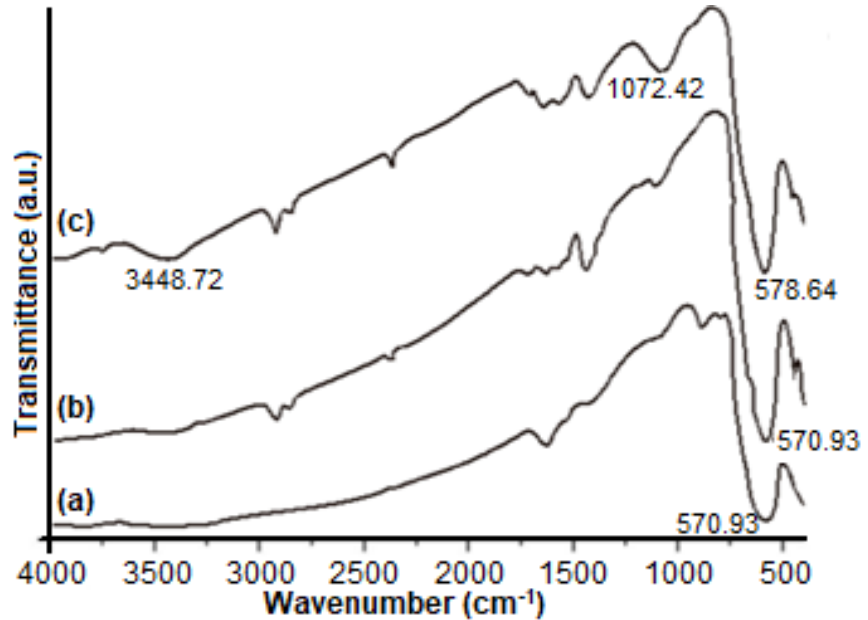

Fig 5. FT-IR spectra of pristine $\mathrm{Fe}_{3} \mathrm{O}_{4} \mathrm{NPs}$ (a), oleic acid modified $\mathrm{Fe}_{3} \mathrm{O}_{4}$ NPs (b) and $\mathrm{Fe}_{3} \mathrm{O}_{4}$-chitosan nanocomposite (c) [14-15]

asymmetric and symmetric stretching band of $\mathrm{COO}^{-}$of oleate [34-35]. The absorption peak near $1110 \mathrm{~cm}^{-1}$ in curve (b) and (c) can be ascribed to the vibration of O$\mathrm{C}-\mathrm{O}$ bond of the oleate. These results indicated that the oleic acid has changed into oleate and coated onto the surface of the $\mathrm{Fe}_{3} \mathrm{O}_{4}$ NPs. The new peak appears at 1627 $\mathrm{cm}^{-1}$ (overlap with other band) come from imine groups, $(\mathrm{N}=\mathrm{C})$ produced by reaction between chitosan with glutaraldehyde [35]. While the shifting of $\mathrm{Fe}_{3} \mathrm{O}_{4}$ characteristic peaks from $571 \mathrm{~cm}^{-1}$ (Fig. 5 (a)) to $579 \mathrm{~cm}^{-}$ ${ }^{1}$ (Fig. 5(b)) indicated possible binding of irons from magnetite to $\mathrm{NH}_{2}$ as well as -OH groups of chitosan. In addition, electrostatic interaction between surface negative charged $\mathrm{Fe}_{3} \mathrm{O}_{4}$ and positively protonated chitosan can also contribute [36].

Based on those explanation, it can be predicted that chitosan has been coated on the oleic acid modified $\mathrm{Fe}_{3} \mathrm{O}_{4}$ nanoparticle successfully. The interaction model was presented on Fig. 6, which to consist of three steps. In the first step, the molecules of oleic acid prevent aglomeration of magnetite particles. In the second step, chitosan molecules interact with nanoparticles of mgnetite-oleic acid via both of $-\mathrm{NH}_{2}$ and $-\mathrm{OH}$ group. While in the third step, glutaraldehyde molecules crosslink the chitosan molecules which have interacted with nanoparticles of magnetite-oleic acid. 

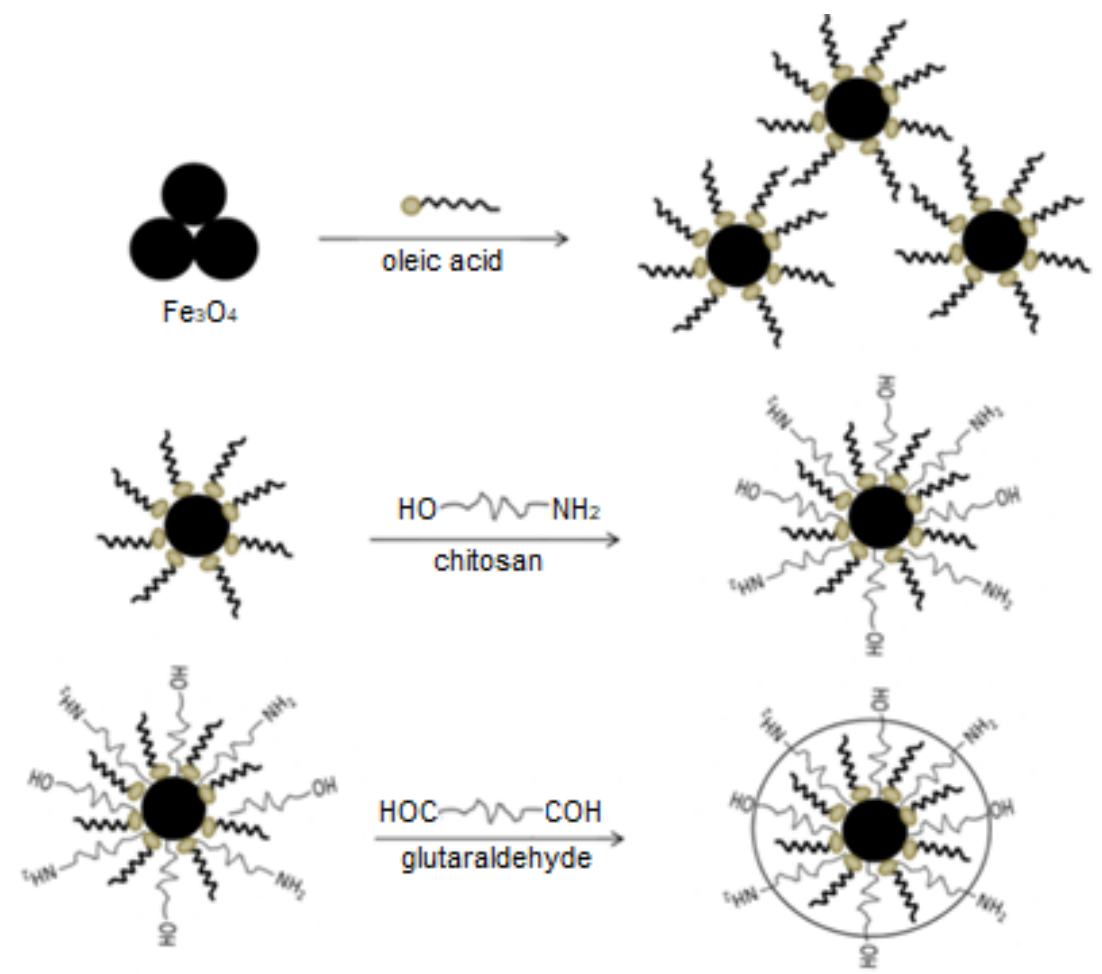

Fig 6. Interaction model in the formation of the nanocomposite

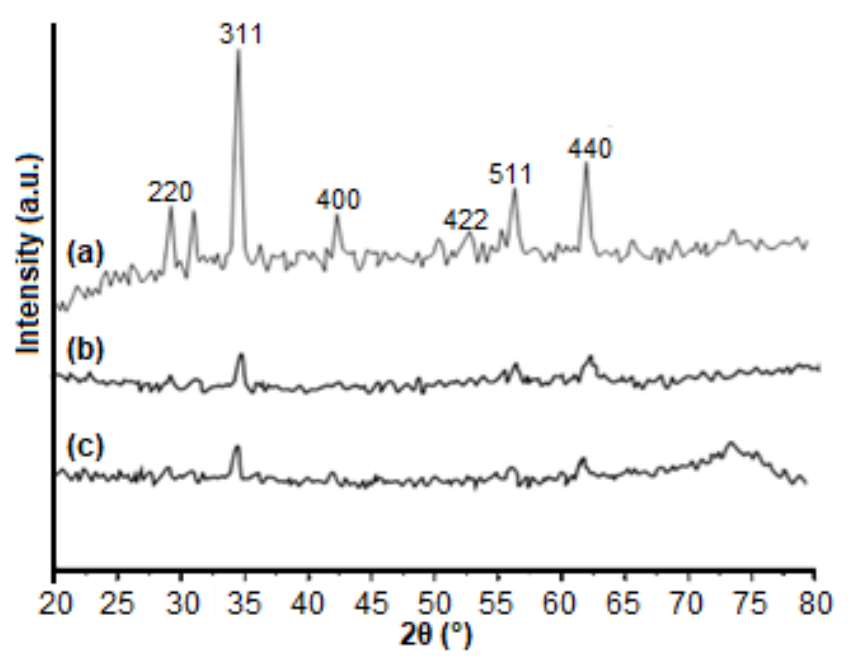

Fig 7. XRD patterns of pristine $\mathrm{Fe}_{3} \mathrm{O}_{4} \mathrm{NPs}(\mathrm{a})$, oleic acid modified $\mathrm{Fe}_{3} \mathrm{O}_{4} \mathrm{NPs}(\mathrm{b})$ and the nanocomposite of $\mathrm{Fe}_{3} \mathrm{O}_{4^{-}}$ chitosan (c) [14-15]

\section{Characterization of Nanocomposite}

Fig. 7 exhibits the XRD patterns comparation of pristine $\mathrm{Fe}_{3} \mathrm{O}_{4} \mathrm{NPs}\left(\mathrm{a}\right.$ ), oleic acid modified $\mathrm{Fe}_{3} \mathrm{O}_{4}$ NPs in optimal condition (b) and nanocomposite of $\mathrm{Fe}_{3} \mathrm{O}_{4^{-}}$ chitosan (c). There are 6 of characteristic peaks for $\mathrm{Fe}_{3} \mathrm{O}_{4}$

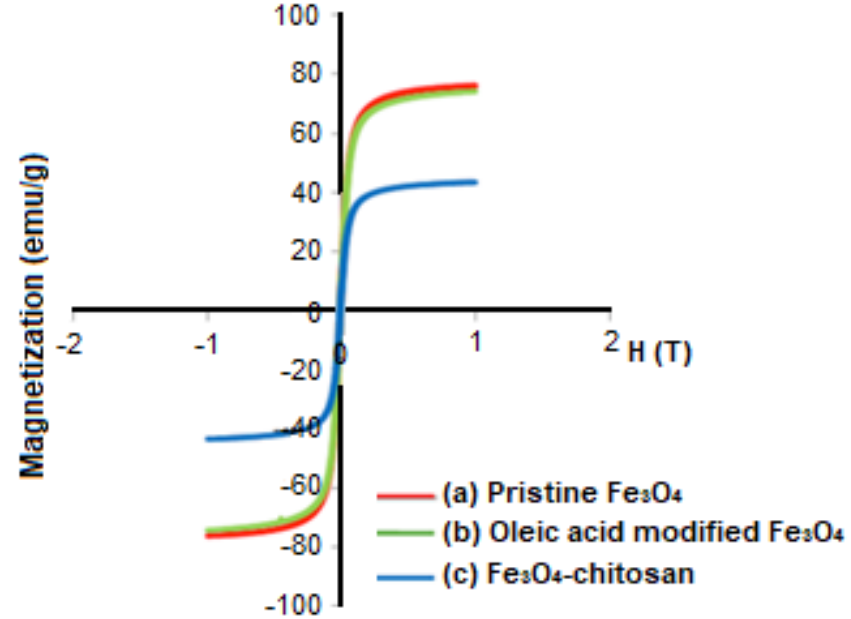

Fig 8. Room temperature magnetization curves for pristine $\mathrm{Fe}_{3} \mathrm{O}_{4}(\mathrm{a})$, oleic acid modified $\mathrm{Fe}_{3} \mathrm{O}_{4} \mathrm{NPs}(\mathrm{b})$ and $\mathrm{Fe}_{3} \mathrm{O}_{4}$-chitosan nanocomposite (c) [14-15]

$\left(2 \theta=30.1,35.4,43.1,53.4,56.9\right.$, and $\left.62.5^{\circ}\right)$ were observed in all of the samples.

These peaks are consistent with the standard pattern for $\mathrm{Fe}_{3} \mathrm{O}_{4}$ (JCPDS no. 79-0418) with a cubic inverse spinel structure. The Quite weak diffraction lines of composite patterns (Fig. 7(c)) indicated that $\mathrm{Fe}_{3} \mathrm{O}_{4}$ particles 

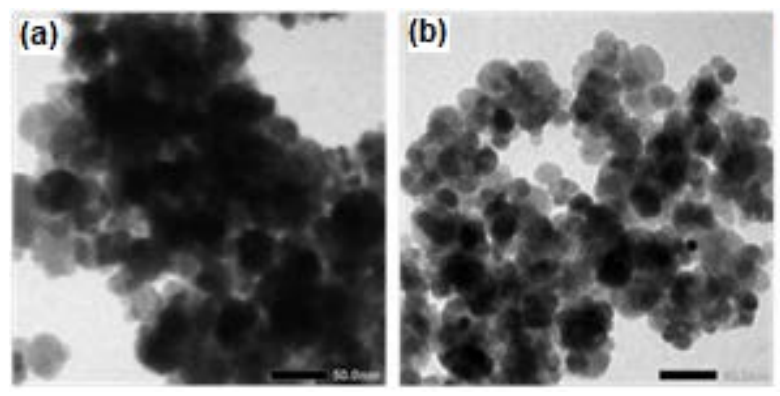

(c)

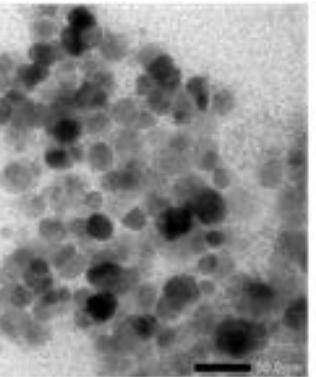

Fig 9. TEM images of pristine $\mathrm{Fe}_{3} \mathrm{O}_{4}$ (a), oleic acid modified $\mathrm{Fe}_{3} \mathrm{O}_{4}(\mathrm{~b})$ and $\mathrm{Fe}_{3} \mathrm{O}_{4}$-chitosan nanocomposite (c) [14-15]

have been coated by amorphous chitosan. It is parallel with interpretation of FTIR spectra. Furthermore, this coating did not change the phase of $\mathrm{Fe}_{3} \mathrm{O}_{4}$. The results showed that the modification did not change the crystal structure of the $\mathrm{Fe}_{3} \mathrm{O}_{4}$ NPs.

The mean crystal sizes were determined by the Debye-Scherrer equation with XRD data, $\mathrm{D}=\mathrm{K} \lambda /(\beta \cos \theta)$, where $\mathrm{K}$ is a constant $(\mathrm{K}=0.94$ for $\mathrm{Cu}-\mathrm{Ka}), \lambda$ is the wavelength $(0.15405 \mathrm{~nm}$ for $\mathrm{Cu}-\mathrm{Ka}), \beta$ the full-width at half maximum (FWHM) of the strongest reflection of the (311) peak, and $\theta$ is the diffraction angle [37]. Based on those equation, the crystal sizes of pristine $\mathrm{Fe}_{3} \mathrm{O}_{4}$, oleic acid modified $\mathrm{Fe}_{3} \mathrm{O}_{4}$ NPs and $\mathrm{Fe}_{3} \mathrm{O}_{4}$ NPs in the nanocomposite of $\mathrm{Fe}_{3} \mathrm{O}_{4}$-chitosan were found to be approximately 23,14 , and $13 \mathrm{~nm}$ respectively.

Magnetic properties of $\mathrm{Fe}_{3} \mathrm{O}_{4}$, oleic acid modified $\mathrm{Fe}_{3} \mathrm{O}_{4}$ and nanocomposite of $\mathrm{Fe}_{3} \mathrm{O}_{4}$-chitosan were characterized by vibrating sample magnetometer (VSM). The magnetic hysteresis curves are shown in Fig. 8, (a) pristine $\mathrm{Fe}_{3} \mathrm{O}_{4} \mathrm{NPs}$ (b) oleic acid modified $\mathrm{Fe}_{3} \mathrm{O}_{4} \mathrm{NPs}$ and (c) Nanocomposite of $\mathrm{Fe}_{3} \mathrm{O}_{4}$-chitosan.

It can be seen that no coercivity or remanence could be observed for all of the three samples, suggesting the superparamagnetic properties of the $\mathrm{Fe}_{3} \mathrm{O}_{4}$ NPs. This can be ascribed to the small size of NPs which were smaller than the superparamagnetic critical size $(25 \mathrm{~nm})$ [38]. The saturation magnetization of pristine $\mathrm{Fe}_{3} \mathrm{O}_{4}$, oleic acid modified $\mathrm{Fe}_{3} \mathrm{O}_{4}$ NPs and nanocomposite of $\mathrm{Fe}_{3} \mathrm{O}_{4-}$ chitosan were 76.0, 74.0 and $43.4 \mathrm{emu} / \mathrm{g}$ respectively. The high saturation magnetization of pristine $\mathrm{Fe}_{3} \mathrm{O}_{4}$ and oleic acid modified $\mathrm{Fe}_{3} \mathrm{O}_{4}$ NPs indicated the good crystal structure. There is no large difference in saturation magnetization between them, because the layer of oleic acid is slight only. On the other hand, saturation magnetization of $\mathrm{Fe}_{3} \mathrm{O}_{4}$-chitosan nanocomposite was much lower than that of the pristine $\mathrm{Fe}_{3} \mathrm{O}_{4}$. This was due to the existence of the large amount of diamagnetic chitosan in the $\mathrm{Fe}_{3} \mathrm{O}_{4}$-chitosan NPs [38]. Although, the values of the saturation magnetization of this work were much larger than the result reported in the literature (22 emu/g) [39].

Fig. 9 shows the TEM images of pristine $\mathrm{Fe}_{3} \mathrm{O}_{4}$, oleic acid modified $\mathrm{Fe}_{3} \mathrm{O}_{4}$, and $\mathrm{Fe}_{3} \mathrm{O}_{4}$-chitosan nanocomposite. It is clear that pristine $\mathrm{Fe}_{3} \mathrm{O}_{4}$ were quite agglomerated, while oleic acid modified $\mathrm{Fe}_{3} \mathrm{O}_{4}$ and $\mathrm{Fe}_{3} \mathrm{O}_{4}$-chitosan nanocomposite particles was looser, less agglomerated, and uniform in particle size. Image of $c$ showed that $\mathrm{Fe}_{3} \mathrm{O}_{4}$-chitosan nanocomposite particles were quasi-spherical and had good dispersity.

The size of $\mathrm{Fe}_{3} \mathrm{O}_{4}$-chitosan nanocomposite particles were 20-25 nm, while of $\mathrm{Fe}_{3} \mathrm{O}_{4}$ particles in the $\mathrm{Fe}_{3} \mathrm{O}_{4}$-chitosan nanocomposite were about $14 \mathrm{~nm}$ which is close to the calculation using the Debye-Scherrer equation in the XRD data. Those images also exhibited the formation of the $\mathrm{Fe}_{3} \mathrm{O}_{4}$-chitosan nanoparticles with core-shell structure which has a different contrasts. The dark areas represent crystalline $\mathrm{Fe}_{3} \mathrm{O}_{4}$, while the bright ones are assigned for amorphous chitosan. In addition, a slight aggregation can be seen which was caused by the crosslinking between the different nanoparticles.

\section{- CONCLUSION}

The as-synthesized $\mathrm{Fe}_{3} \mathrm{O}_{4}$-chitosan nanocomposite had good crystal structure with a cubic inverse spinel structure, monodisperse and quite sphere in shape with diameter of 20-25 nm. The particle size of $\mathrm{Fe}_{3} \mathrm{O}_{4}$ in the nanocomposite was about $14 \mathrm{~nm}$ with narrow in size distribution. The $\mathrm{Fe}_{3} \mathrm{O}_{4}$-chitosan nanocomposite 
exhibited high saturation magnetization $(43.4 \mathrm{emu} / \mathrm{g})$ and superparamagnetic property. There are interaction between $\mathrm{Fe}_{3} \mathrm{O}_{4}$ nanoparticles and chitosan in which irons from magnetite interact with $-\mathrm{NH}_{2}$ as well as $-\mathrm{OH}$ groups of chitosan. Additionally, electrostatic interaction between surface negative charged $\mathrm{Fe}_{3} \mathrm{O}_{4}$ and positively protonated chitosan can also contribute.

\section{- ACKNOWLEDGMENTS}

The authors are grateful to the Department of High Education and Research of Republic Indonesia which via Universitas Gadjah Mada has funded the research.

\section{- REFERENCES}

[1] Futalan, C.M., Khan, C.C., Dalida, M.L.P., Pascua, C., Hsien, K.J., and Wan, M.W., 2011, Nickel removal from aqueous solution in fixed bed Using chitosan coated bentonite, Sustainable Environ. Res., 21 (6), 361-367.

[2] Ramya, R., Sankar, P., Anbalagan, S., and Sudha, P.N., 2011, Adsorption of $\mathrm{Cu}(\mathrm{II})$ and $\mathrm{Ni}(\mathrm{II})$ ions solutions using crosslinked chitosan polymer, Int. $J$ Environ. Sci., 1 (6), 1323-1338

[3] Divakaran, R., Paul, A., Anoop, A.J., Kuriakose, K.K.A., and Rajesh, V.J.R., 2012, Adsorption of nickel(II) and chromium(VI) ions by chitin and chitosan from aqueous solutions containing Both ions, Int. J. Sci. Technol. Res., 1, 43-50.

[4] Zheng, W., Li, X.M., Yang, Q., Zeng, G.M., Shen, X.X., Zhang, J., and Liu, J.J., 2007, Adsorption of $\mathrm{Cd}(\mathrm{II})$ and $\mathrm{Cu}(\mathrm{II})$ from aqueous solution by carbonate hydroxyapatite derived from egg shell waste, J. Hazard. Mater., 147 (1-2), 534-539.

[5] Yan, H., Yang, L., Yang, Z., Yang, H., Li, A., and Cheng, R., 2012, Preparation of chitosan/poly(acrylic acid) magnetic composite microspheres and applications in the removal of copper(II) ions from aqueous solutions, J. Hazard. Mater., 229-230, 371380.

[6] Akkaya, R., and Ulusoy, U., 2008, Adsorptive features of chitosan entrapped in polyacrylamide hydrogel for $\mathrm{Pb}^{2+}, \mathrm{UO}_{2}{ }^{2+}$, and $\mathrm{Th}^{4+}$, J. Hazard. Mater., $151(2-3), 380-388$.
[7] Kushwaha, S., and Sudhakar, P.P., 2011, Adsorption of mercury(II), methyl mercury(II) and phenyl mercury(II) on chitosan crosslinked with a barbital derivative, Carbohydr. Polym., 86 (2), 1055-1062.

[8] Wen, Y., Tang, Z., Chen, Y, and Gu, Y., 2011, Adsorption of $\mathrm{Cr}(\mathrm{VI})$ from aqueous solutions using chitosan-coated fly ash composite as biosorbent, Chem. Eng. J., 175, 110-116.

[9] Ambashta, R.D., and Sillanpaa, M., 2010, Water purification using magnetic assistance: A review, $J$. Hazard. Mater., 180 (1-3), 38-49.

[10] Petrova, T.M., Fachikov, L., and Hristov, J., 2011, The magnetite as adsorbent for some hazardous species from aqueous solutions: A review, Int., Rev. Chem. Eng., 3, 134-152.

[11] Zureick, A.H., Shih, B., and Munley, E., 1995, Fiberreinforced polymeric bridge decks, Struct. Eng. Rev., 7 (3), 257-266.

[12] Shete, P.B., Patil, R.M., Tiwale, B.M., and Pawar, S.H., 2015, Water dispersible oleic acid-coated $\mathrm{Fe}_{3} \mathrm{O}_{4}$ nanoparticles for biomedical applications, $J$. Magn. Magn. Mater., 377, 406-410.

[13] Patil, R.M., Shete, P.B., Thorat, N.D., Otari, S.V., Barick, K.C., Prasad, A.I., Ningthoujam, R.S., Tiwale, B.M., Pawar, S.H., 2014, Non-aqueous to aqueous phase transfer of oleic acid coated iron oxide nanoparticles for hyperthermia application, RSC Adv., 4 (9), 4515-4522.

[14] Kusumaningrum, H., 2016, Sintesis Komposit Kitosan-Magnetit Termodifikasi Asam Oleat dan Kajian Kelayakannya sebagai Adsorben $\mathrm{Hg}(\mathrm{II})$, Undergraduate Thesis, Department of Chemistry, Universitas Gadjah Mada, Yogyakarta.

[15] Kurnia, L., 2016, Sintesis Komposit KitosanMagnetit Termodifikasi Asam Oleat dan Aplikasinya sebagai Adsorben Cr(III) dalam Larutan Berair, Undergraduate Thesis, Department of Chemistry, Universitas Gadjah Mada, Yogyakarta.

[16] Kumar, N.S., Suguna, M., Subbaiah, M.V., Reddy, A.S., Kumar, N.P., and Krishnaiah, 2010, Adsorption of phenolic compounds from aqueous 
solution onto chitosan-coated perlite beads as biosorbent, Ind. Eng. Chem. Res., 49 (19), 9238-9247.

[17] Kumari, S., Rath, P., and Kumar, A.S.H., 2016, Chitosan from shrimp shell (Crangon crangon) and fish scales (Labeorohita): Extraction and characterization, Afr. J. Biotechnol., 15 (24), 12581268.

[18] Soni, U., Bajpai, J., and Bajpai, A.K., 2015, Chitosanactivated carbon nanocomposites as potential biosorbent for removal of nitrophenol from aqueous solutions, Int. J. Nanomater. Biostruct., 5 (4), 53-61.

[19] Kweon, H.Y., Um, I.C., and Park, Y.H., 2001, Structural and thermal characteristics of Antheraea pernyi silk fibroin/chitosan blend film, Polymer, 42 (15), 6651-6656.

[20] Hajji, S., Younes, I., Ghorbel-Bellaa, O., Hajji, R., Rinaudo, M., Nasri, M., and Jellouli, K., 2014, Structural differences between chitin and chitosan extracted from three different marine sources, Int. J. Biol. Macromol., 65, 298-306.

[21] Chouwatat, P., Polsana, P., Noknoi, P., Siralertmukul, K., and Srikulkit, K., 2010, Preparation of hydrophobic chitosan using complexation method for PLA/chitosan blend, $J$. Met. Mater. Miner., 20 (1), 41-44.

[22] Choi, C.Y., Kim, S.B., Pak, P.K., Yoo, D.I., and Chung, Y.S., 2007, Effect of $N$-acylation on structure and properties of chitosan fibers, Carbohydr. Polym., 68 (1), 122-127.

[23] Li, Q., Weng, S., Wu, J., and Zhou, N., 1998, Comparative study on structure of solubilized water in reversed micelles. 1. FT-IR spectroscopic evidence of water/AOT $/ n$-heptane and water $/ \mathrm{NaDEHP} / n$ heptane systems, J. Phys. Chem. B, 102 (17), 31683174.

[24] Nouri, M., Khodaiyan, F., Razavi, S.H., and Mousavi, M., 2016, Improvement of chitosan production from Persian Gulf shrimp waste by response surface technology, Food Hydrocolloids, 59, 50-58.

[25] Alishahi, A., Mirvaghefi, A., Tehrani, M.R., Farahmunh, H., Shojaosadati, S.A., Dorkoosh, F.A., and Maher, Z.E., 2011, Enhancement and characterization of chitosan extraction from the wastes of shrimp packaging plants, J. Polym. Environ., 19 (3), 776-783.

[26] Yen, M.T., and Mau, J.L., 2007, Physico-Chemical Characterization of fungal chitosan from shiitake stipes, LWT Food Sci. Technol., 40 (3), 472-479.

[27] Yen, Ming-Tsung, Y., Joan-Hwa, Y., and JengLeun, M., 2009, Physicochemical characterization of chitin and chitosan from crab shells, Carbohydr. Polym., 75 (1), 15-21.

[28] Vaidyanathan, G., Sendhilnathan, S., and Arulmurugan, R., 2007, Structural and magnetic properties of $\mathrm{Co}_{1-x} \mathrm{Zn}_{x} \mathrm{Fe}_{2} \mathrm{O}_{4}$ nanoparticles by coprecipitation method, J. Magn. Magn. Mater., 313 (2), 293-299.

[29] López, J.A., González, F., Bonilla, F.A., Zambrano, G., and Gómez, M.E., 2010, Synthesis and characterization of $\mathrm{Fe}_{3} \mathrm{O}_{4}$ magnetic nanofluid, Rev. Latinoam. Metal. Mater., 30 (1), 60-66.

[30] Vasile, E., Serafim, A., Dragusin, D.M., Petrea, C., Iovu, H., and Stancu, I.C., 2012, Apatite formation on active nanostructured coating based on functionalized gold nanoparticles, J. Nanopart. Res., 14, 918.

[31] Biswas, S., Srivastava, V.K., and Ram, S., 2007, Nanorods of silver-coated magnetic $\mathrm{CrO}_{2}$ particles from a polymer template in hot water, J. Phys. Chem. C, 111 (21), 7593-7598.

[32] Morales, M.P., Veintemillas-Verdaguer, S., Montero, M.I., Serna, C.J., Roig, A., Casas, L., Martinez, B., and Sandiumenge, F., 1999, Surface and internal spin canting in $\gamma-\mathrm{Fe}_{2} \mathrm{O}_{3}$ nanoparticles, Chem. Mater., 11 (11), 3058-3064.

[33] Zhang, L., He, R., and Gu, H.C., 2006, Oleic acid coating on the monodisperse magnetite nanoparticles, Appl. Surf. Sci., 253 (5), 2611-2617.

[34] Ho, K.M., and Li, P., 2008, Design and synthesis of novel magnetic core-shell polymeric particles, Langmuir, 24 (5), 1801-1807.

[35] Dung, D.T.K., Hai, T.H., Phuc, L.H., Long, B.D., Vinh, L.K., and Truc, P.N., 2009, Preparation and characterization of magnetic nanoparticles with chitosan coating, J. Phys. Conf. Ser., 187, 012036. 
[36] Tran, H.V., Tran, L.D., and Nguyen, T.N., 2010, Preparation of chitosan/magnetite composite beads and their application for removal of $\mathrm{Pb}$ (II) and $\mathrm{Ni}$ (II) from aqueous solution, Mater. Sci. Eng., C, 30 (2), 304-310.

[37] Pradhan, P., Giri, J., Samanta, G., Sarma, H.D., Mishra, K.P., Bellare, J., Banerjee, R., and Bahadur, D., 2006, Comparative evaluation of heating ability and biocompatibility of different ferrite-based magnetic fluids for hyperthermia application, $J$. Biomed. Mater. Res. Part B, 81 (1), 12-22.
[38] Jordan, A., Scholz, R., Wust, P., Fähling, H., and Felix, R., 1999, Magnetic fluid hyperthermia (MFH): Cancer treatment with AC magnetic field induced excitation of biocompatible superparamagnetic nanoparticles, J. Magn. Magn. Mater., 201 (1-3), 413-419.

[39] Donadel, K., Felisberto, M.D.V., Fávere, V.T., Rigoni, M., Batistela, N.J., and Laranjeira, M.C.M., 2008, Synthesis and characterization of the iron oxide magnetic particles coated with chitosan biopolymer, Mater. Sci. Eng., C, 28 (4), 509-514. 